\title{
Crosslinking and Ageing of Ethylene-Vinyl Silane Copolymer in Water Bath
}

\author{
Petra Trňáčkováa, Miroslav Pastorek ${ }^{\mathrm{a}, \mathrm{b}}$, Roman Čermák ${ }^{\mathrm{a}, \mathrm{b}}$, Martina Poláškováa ${ }^{\mathrm{a}, \mathrm{b}}$ \\ ${ }^{a}$ Department of Polymer Engineering, Faculty of Technology, Tomas Bata University in Zlin, \\ nám. T. G. Masaryka 275, 76272 Zlín, Czech Republic \\ ${ }^{b}$ Centre of Polymer Systems, University Institute, Tomas Bata University in Zlin, \\ nám. T. G. Masaryka 5555, 76001 Zlín, Czech Republic
}

\begin{abstract}
The paper focuses on chemical and morphological changes of ethylene-vinyl silane copolymer upon exposure to hot water. Within processing, the exposure to hot water is the final step causing crosslinking and stabilization of material against high temperatures, which can occur in application to wire insulation. For these purposes, commercially available copolymer and catalytic system have been used. A strong effect of catalytic system on kinetics of crosslinking and subsequently ageing was observed. Chemical evolution was followed by infrared spectroscopy and differential scanning calorimetry was involved for evaluation of morphological changes.
\end{abstract}

Keywords: ethylene-vinyl silane copolymer, ageing, hot water, infrared spectroscopy, differential scanning calorimetry PACS: $61.25 . \mathrm{hp}$

\section{INTRODUCTION}

Polyethylene (PE) is beside polyvinylchloride (PVC) one of the most frequently applied polymer in wire insulations. In 1950, it has been introduced for electrical and transmission cables, followed by underground applications. In comparison with PVC, PE is less thermally stable and flame resistant. Fortunately, these properties can be improved by crosslinking [1].

Crosslinking causes intermolecular chemical bonding of polyethylene chains. As a consequence, the material exhibits common behavior of thermoplastics below its melting temperature $\left(T_{m}\right)$, and rubber viscoelasticity above $\mathrm{T}_{\mathrm{m}}$. PE possesses no functional groups which would provide the possibility of crosslinking, therefore, a specific approach has to be employed to achieve network structure $[2,3]$. The saturated structure of PE can be crosslinked by peroxides, high-energy irradiation and silane group incorporation.

For silane-assisted crosslinking of PE, presence of water is an important prerequisite. In the first step, the silane groups are hydrolyzed. Then, the silanol groups can condense creating siloxane linkages between the polymer chains. These reactions proceed in both, the melt and solid state. The significant improvement of crosslinking homogeneity in silane-modified polyethylene can be achieved by the addition of catalytic systems [4, 5].

In the industry scale, the crosslinking of silane-modified $\mathrm{PE}$ is rather performed in $90{ }^{\circ} \mathrm{C}$ hot water bath. At such conditions the material is in close vicinity to its $\mathrm{T}_{\mathrm{m}}$ and not only chemical but also morphological changes can be expected [6].

The present work focuses on the effect of catalytic system and exposure to hot water on crosslinking and ageing of ethylene-vinyl silane copolymer. For these purposes, neat and catalyzed materials have been exposed to $90{ }^{\circ} \mathrm{C}$ hot water for 0-720 hours. Changes in molecular structure and morphology were determined by a combination of experimental methods.

\section{MATERIAL AND METHODS}

Ethylene-vinyl silane copolymer LE 4423 (EVS) was used in this work. The material is produced within highpressure VISICO method and was catalyzed by 5 wt. \% of AMBICAT LE 4476 catalytic master batch (CS) supplied by Borealis AB.

6th International Conference on Times of Polymers (TOP) and Composites
AIP Conf. Proc. 1459, 55-57 (2012); doi: 10.1063/1.4738396

(C) 2012 American Institute of Physics 978-0-7354-1061-9/\$30.00 
Neat EVS and catalyzed (EVS+CS) were extruded in strip form using a Brabender extruder. The extruded strip was cut to pieces. The strips were placed in a bath with distilled water for 0-30 days at $90{ }^{\circ} \mathrm{C}$ and taken at certain time intervals to be analyzed.

To measure infrared transmission spectra of the $100 \mu \mathrm{m}$ thick samples, the equipment FTIR AVATAR 320 NICOLET with a resolution $2 \mathrm{~cm}^{-1}$ was used. The measured range was from $4000 \mathrm{~cm}^{-1}$ to $550 \mathrm{~cm}^{-1}$ and number of scans was 32 .

All the samples were analyzed by differential scanning calorimeter (Perkin Elmer Pyris -1 instrument). The measurements were carried out in a nitrogen atmosphere. The specimens were cut out from the extruded tapes and loaded into standard aluminum pans.

The following temperature mode was used: $1^{\text {st }}$ heating $40{ }^{\circ} \mathrm{C}-120{ }^{\circ} \mathrm{C}$, cooling $120{ }^{\circ} \mathrm{C}-40{ }^{\circ} \mathrm{C}, 2^{\text {nd }}$ heating $40{ }^{\circ} \mathrm{C}-120{ }^{\circ} \mathrm{C}$. In all the cases heating/cooling rate was $10^{\circ} \mathrm{C} / \mathrm{min}$.

\section{RESULTS AND DISCUSSION}

Crosslinking of ethylene-vinyl silane copolymer can be monitored by infrared spectroscopy. Within this process, characteristic peaks of the methoxy groups $\left(\mathrm{Si}-\mathrm{O}-\mathrm{CH}_{3}\right)$ decrease as a consequence of water hydrolysis. On the other hand, an increase of the characteristic peaks of siloxane groups ( $\mathrm{Si}-\mathrm{O}-\mathrm{Si}$ ) can be seen due to condensation. yIn Figure 1, a gradual decrease of peak intensity at $1095 \mathrm{~cm}^{-1}\left(\mathrm{Si}-\mathrm{O}-\mathrm{CH}_{3}\right)$ and an increase of peaks at $1065 \mathrm{~cm}^{-1}$ and $1025 \mathrm{~cm}^{-1}$ (Si-O-Si) reflect the crosslinking. As shown in Figure 1a, the kinetics of crosslinking reaction in neat EVS is rather slow; the equilibrium stage is achieved after 480 hours exposure to hot water. A significant effect of catalytic system on crosslinking kinetics is demonstrated in Figure 1b; EVS+CS reached the saturated level after 96 hours and following hot water exposure did not cause any significant chemical changes.

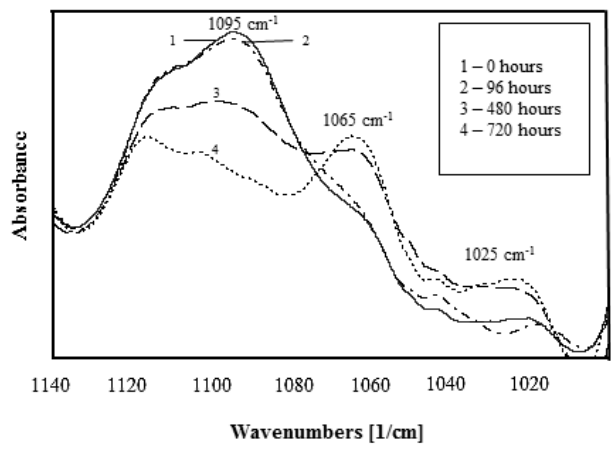

(a)

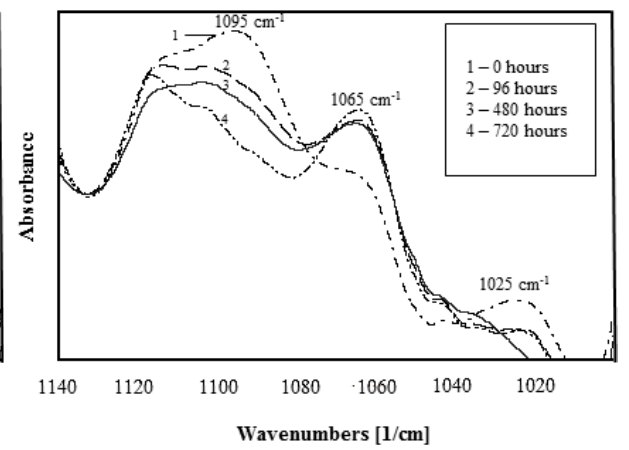

(b)

FIGURE 1. Infrared spectra of (a) EVS and (b) EVS+CS upon exposure to hot water

Differential scanning calorimetry allows monitoring of changes in the morphology induced by the exposure to hot water. Figure 2 shows the endothermic curves of $1^{\text {st }}$ heating of EVS and EVS+CS reflecting the melting of supermolecular structure originated from processing and subsequent hot water exposure. It is seen that both materials exhibit only one melting peak immediately after processing. Upon exposure to hot water, an evolution of melting peak at $97{ }^{\circ} \mathrm{C}$ can be detected. With further exposure, $\mathrm{T}_{\mathrm{m}}$ peak moves towards higher temperatures. This demonstrates partial recrystallization and further improvement of supermolecular structure due to exposure to temperature $\left(90^{\circ} \mathrm{C}\right)$ close to the $\mathrm{T}_{\mathrm{m}}$ of materials.

In Figure 3, the thermograms of $2^{\text {nd }}$ heating of EVS and EVS+CS are shown. In fact, these curves show the crystallizability and subsequent thermodynamic stability of crystallites upon crosslinking in hot water. In both cases, only one melting peak is detected. Upon the hot water exposure, the $\mathrm{T}_{\mathrm{m}}$ gradually changes from 108 to $104{ }^{\circ} \mathrm{C}$. It is interesting to note that the lower $\mathrm{T}_{\mathrm{m}}$ limit $\left(104{ }^{\circ} \mathrm{C}\right)$ is reached in both materials at the exposure time which corresponds to saturation time of crosslinking evaluated from infrared spectroscopy (480 hours for EVS and 96 hours for EVS+CS). 


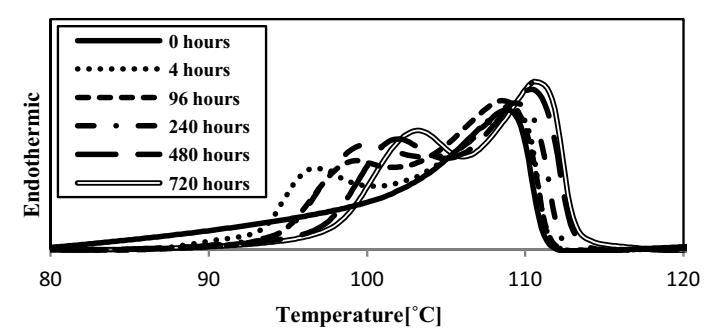

(a)

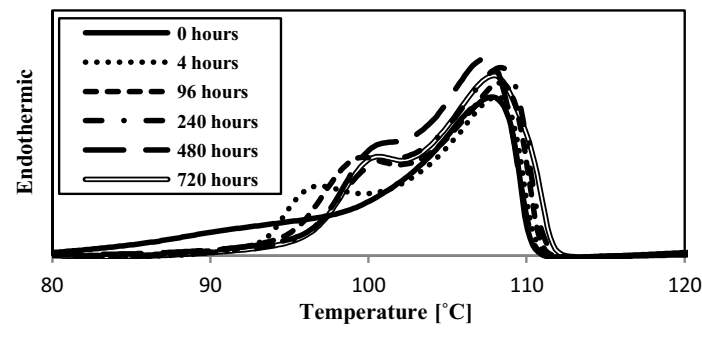

(b)

FIGURE 2. DSC thermograms of endothermic curves of $1^{\text {st }}$ heating upon hot water exposure: (a) EVS, (b) EVS+CS

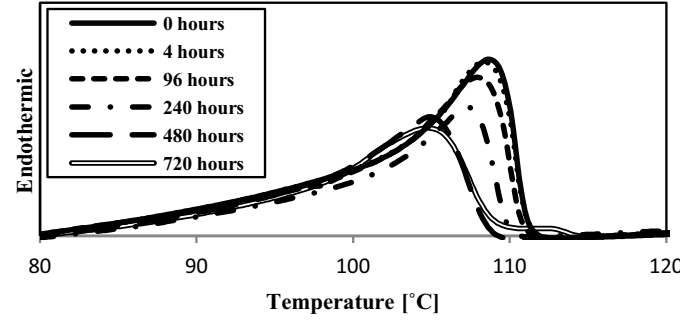

(a)

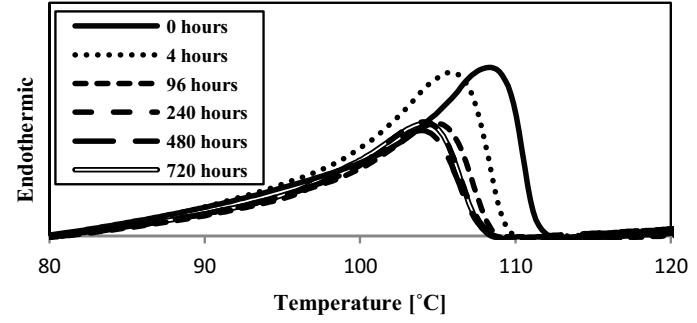

(b)

FIGURE 3. DSC thermograms of endothermic curves of $2^{\text {nd }}$ heating upon hot water exposure: (a) EVS, (b) EVS+CS

\section{CONCLUSION}

The aim of this work was to determine the effects of catalytic system and exposure to hot water on the evolution of chemical structure and morphology of ethylene-vinyl silane copolymer. It was demonstrated that incorporation of catalytic system dramatically accelerates the crosslinking kinetics of this material. Exposure to hot water causes not only crosslinking of EVS, but also partial recrystallization of amorphous phase reflecting in evolution of the second melting peak in the range of $97-103{ }^{\circ} \mathrm{C}$. It was found that the presence of catalyst masterbatch influenced both crosslinking and ageing. Substantial changes occurred in neat EVS upon the whole exposure to hot water.

\section{ACKNOWLEDGMENTS}

The work was supported by the Operational Programme Research and Development for Innovations cofunded by the European Regional Development Fund (ERDF) and national budget of Czech Republic within the framework of the Centre of Polymer Systems project (reg. no.: CZ.1.05/2.1.00/03.0111). Petra Trňáčková and Miroslav Pastorek gratefully acknowledge the financial support of this work by the internal grant of TBU in Zlín, No. IGA/FT/2012/040, funded from the resources of specific university research.

\section{REFERENCES}

1. Y.T. Shieh, J. S. Chen and C. C. Lin, Thermal fractionation and crystallization enhancement of silane-grafted watercrosslinked low-density polyethylene, Journal of Applied Polymer Science, 2001, pp. 591-599.

2. F. Ciuprina, G. Teissedre and J. C. Filippini, Polyethylene crosslinking and water treeing, Polymer, 2001, pp. 7841-7846.

3. H. A. KHONAKDAR, J. MORSHEDIAN, U. WAGENKNECHT and S. H. JAFARI, An investigation of chemical crosslinking effect on properties of high-density polyethylene, Polymer 44, 2003, Vol. 4301, pp. 4301-4309.

4. M. Palmlöf, Crosslinking of ethylene copolymers, Thesis for the degree of Doctor of Philosophy Göteborg: Chalmers University of Technology, 1999, pp. 1-14.

5. K. SIRISINHA and S. CHIMDIST, Comparison of techniques for determining crosslinking in silane - water crosslinked materials, Polymer testing 25; 2006; pp. 518-526.

6. M. Pastorek, R. Čermák, J. Navrátilová and M. Obadal, Thermal ageing of crosslinked ethylene-vinyl silane copolymers, Society of Plastics Engineers Annual Technical Conference 2009, 2009, pp. 1-5. 
Copyright of AIP Conference Proceedings is the property of American Institute of Physics and its content may not be copied or emailed to multiple sites or posted to a listserv without the copyright holder's express written permission. However, users may print, download, or email articles for individual use. 